\title{
Design, Synthesis, and Pharmacological Screening of Novel Porphyrin Derivatives
}

\author{
Ahmed A. Fadda, ${ }^{1}$ Rasha E. El-Mekawy, ${ }^{1}$ Ahmed El-Shafei, ${ }^{2}$ Harold S. Freeman, \\ David Hinks, ${ }^{2}$ and Manal El-Fedawy ${ }^{1}$ \\ ${ }^{1}$ Department of Chemistry, Faculty of Science, Mansoura University, Mansoura, Egypt \\ ${ }^{2}$ Polymer and Color Chemistry Program, North Carolina State University, Raleigh, NC 27695, USA
}

Correspondence should be addressed to Ahmed A. Fadda; afadda50@yahoo.com

Received 24 June 2012; Accepted 2 December 2012

Academic Editor: M. Akhtar Uzzaman

Copyright (C) 2013 Ahmed A. Fadda et al. This is an open access article distributed under the Creative Commons Attribution License, which permits unrestricted use, distribution, and reproduction in any medium, provided the original work is properly cited.

\begin{abstract}
A series of porphyrin derivatives $\mathbf{2 a - f}$ was synthesized, namely, 5,10,15,20-mesotetrakis[ $p$-methoxyphenyl]-21H,23H-porphyrin (2a), 5,10,15,20-mesotetrakis[2,6-dichloro-phenyl]dimethoxyphenyl-21H,23H-porphyrin (2b), 5,10,15,20-mesotetrakis[4-hydroxy3,5-dimethoxyphenyl]-21H,23H-porphyrin (2c), 5,10,15,20-mesotetrakis[3,4-dimethoxyphenyl]-21H,23H-porphyrin (2d), 5,10, 15,20-mesotetrakis[2,4-dichlorophenyl]-21H,23H-porphyrin (2e), and 5,10,15,20-mesotetrakis[3,4,5-trimethoxyphenyl]-21H,23Hporphyrin (2f), in high yields using a new method via a capping mechanism. These dyes were used as a model to study the free radical-induced damage of biological membranes and the protective effects of these porphyrins. It was demonstrated that these dyes were effective in the inhibition of the free radical-induced oxidative haemolysis of rat blood cells. Dyes $\mathbf{2 d}$ and $\mathbf{2 f}$ which bear methoxy functionality exhibited markedly higher antihaemolysis activity than the other analogs. Molecular modeling methods using ZINDO/INDO-1, with a configuration interaction of 26, and TD-DFT using the energy functional B3LYP and the basis set DGTZVP were used to study the vertical electronic excitations of porphyrins $\mathbf{2 a}-\mathbf{f}$ and it was shown that the $\lambda_{\max }$ calculated using TD-DFT method was in excellent agreement with the experimental results, while the ZINDO method was inferior. Moreover, excellent correlation between the LUMO energy and cytotoxicity of dyes $\mathbf{2 a}-\mathbf{f}$ was found.
\end{abstract}

\section{Introduction}

Meso-substituted porphyrins were widely used as key components in constructing porphyrin-based model systems as well as molecular materials [1-4]. The design and synthesis of basic porphyrin building blocks for the construction of highly ordered systems often require incorporation of different peripheral substituents.

The synthesis of porphyrins bearing specific patterns of functionality is still a challenging task in spite of the ample presence of reported procedure $[1,2]$. The difficulties also arise from the separation, purifications, and limited availability of suitable precursors. Although synthetic routes to various porphyrins were reported [5-10], porphyrin building blocks bearing specific peripheral substituents are not available yet. The molecular weight of the porphyrins without any peripheral substituents is considerably lower than the porphyrins bearing substituents at meso- or $\beta$-pyrrolic positions. Keeping the molecular weight of porphyrins low was shown to be important in medical application [11].

Most of the reported methods for porphyrin synthesis generally adopted acid-catalyzed condensation of dipyrromethanes with appropriate aldehydes for the construction of porphyrins. For example, in the 1980s, a new approach for the synthesis of meso-substituted porphyrins under gentle conditions was developed, namely, two-step one flask room temperature synthesis of porphyrins or the Lindsey method [12]. Various facts were considered when designing this method. First, the Rothemund and Adler-Longo method $[13,14]$ employed harsh reaction conditions leading to the formation of porphyrins in low yields. In addition, the synthesis of porphyrins bearing sensitive functional groups 
could not be achieved. As a result of these drawbacks, the need to accomplish the condensation reaction under gentle conditions became an obvious requirement. Secondly, mild conditions were also desirable in order to avoid the side reactions leading to undesired oligomers and other byproducts.

Porphyrins were reported to exhibit a variety of biological activities. The desirable cancer preventive or putative therapeutic properties of porphyrins were also considered to be associated with their antioxidant properties, since free radical-mediated peroxidation of membrane lipids and oxidative damage of DNA were believed to be associated with a variety of chronic health problems, such as cancer, atherosclerosis, neurodegenerative diseases, and ageing [15]. Therefore, the past few years witnessed intense research devoted to the antioxidant activity of porphyrins. For instance, studies pertaining to the kinetics and mechanisms of natural antioxidants [16-18] have demonstrated that simple structural modification of resveratrol, an antioxidant in red wine, significantly enhances its antioxidant activity [19-22] and cytotoxicity towards cancer cells [23].

With this background in mind, we report herein results from the synthesis of a series of porphyrin derivatives and an in vitro study of their protective effects on free radicalinduced haemolysis of rat red blood cells (RBCs). RBC membranes are rich in polyunsaturated fatty acids which are very susceptible to free radical-mediated peroxidation, leading to membrane damage and haemolysis. The peroxidation was initiated by $2,2^{\prime}$-azo-bis(2-amidinopropane hydrochloride) (AAPH), which decomposes at physiological temperature and generate alkyl radicals to initiate lipid peroxidation (see (1), vide infra). Since AAPH is water-soluble and the generation rate of free radicals from the decomposition of AAPH can be easily controlled and measured, it was extensively used as a free radicals initiator for biological and related studies [24] and AAPH-induced haemolysis provides a good experimental approach for studying free radicalinduced membrane damage $[25,26]$.

Thermal decomposition of AAPH in the aqueous dispersion of RBCs produces an initiating radical $\left(\mathrm{R}^{\circ}\right)$ which can attack the polyunsaturated lipids (LH) in RBC membranes to induce lipid peroxidation (see (1)-(6)). The initiation rate of $\mathrm{AAPH}$ at $37^{\circ} \mathrm{C}$ in aqueous dispersions was determined to be $1.3 \times 10^{-6}[\mathrm{AAPH}] / \mathrm{s}$. Since the lipid peroxidation is a free radical chain reaction and one initiating radical could induce up to fifty propagation reactions, the RBC membrane is quickly damaged, leading to haemolysis. On the other hand, if antioxidants (AHs), such as vitamin E, vitamin C, and curcumin, are present or added to RBCs they would react with the chain-propagating peroxyl radicals to stop the peroxidation (see (7)) and, hence, inhibit haemolysis:

Initiation:

$$
\begin{gathered}
\mathrm{R}-\mathrm{N}=\mathrm{N}-\mathrm{R} \longrightarrow 2 \mathrm{R}^{\bullet}+\mathrm{N}_{2} \\
\mathrm{R}^{\bullet}+\mathrm{O}_{2} \longrightarrow \mathrm{ROO} \\
\mathrm{ROO}^{\bullet}+\mathrm{LH} \longrightarrow \mathrm{ROOH}+\mathrm{L}^{\bullet}
\end{gathered}
$$

Propagation:

$$
\begin{aligned}
& \mathrm{L}^{\bullet}+\mathrm{O}_{2} \longrightarrow \mathrm{LOO}^{\bullet} \\
& \mathrm{LOO}^{\bullet}+\mathrm{LH} \longrightarrow \mathrm{LOOH}+\mathrm{L}^{\bullet}
\end{aligned}
$$

Termination:

$$
\mathrm{LOO}^{*}+\mathrm{LOO}^{\bullet} \longrightarrow \text { molecular products }
$$

Antioxidant:

$$
\mathrm{LOO}^{\circ}+\mathrm{AH} \longrightarrow \mathrm{LOOH}+\mathrm{H}^{\bullet}
$$

The dyes studied were 5,10,15,20-mesotetrakis [ $p$-methoxyphenyl]-21H,23H-porphyrin (2a), 5,10,15,20-mesotetrakis[2,6-dichlorophenyl]-21H,23H-porphyrin (2b), 5,10,15,20mesotetrakis[4-hydroxy-3,5-dimethoxyphenyl]-21H,23H-porphyrin (2c), 5,10,15,20-mesotetrakis[3,4-dimethoxyphenyl]$21 \mathrm{H}, 23 \mathrm{H}$-porphyrin (2d), 5,10,15,20-mesotetrak-is[2,4-dichloro-phenyl]-21H,23H-porphyrin (2e), and 5,10,15,20-mesotetrakis[3,4,5-trimethoxy-phenyl]-21H,23H-porphyrin(2f).

\section{Experimental}

2.1. Chemistry. All melting points were uncorrected in degree centigrade and determined on a Gallenkamp electric melting point apparatus. The IR spectra were recorded $(\mathrm{KBr}$ disk) on a Mattson 5000 FTIR Spectrometer at Faculty of Science, Mansoura University. The ${ }^{1} \mathrm{H}-\mathrm{NMR}$ spectra were measured on $200 \mathrm{MHZ}$ Bruker WP 300, using DMSO, $\mathrm{CDCl}_{3}$ as solvents, and TMS as the internal standard, at the Microanalytical Center, Faculty of Science, Cairo University. Ultraviolet spectra were carried recorded using Unicam $\mathrm{UV}_{2}$ UV/Vis. Spectrometer at the Microanalytical Unit, Chemistry Department, Faculty of Science, Mansoura University. The starting materials for syntheses were obtained from Aldrich Chemical Company unless otherwise stated. Pyrrole was distilled under argon with the fraction boiling at $140^{\circ} \mathrm{C}$ collected. $\mathrm{N}, \mathrm{N}$-Dimethylformamide ( $99.9 \%$ anhydrous grade) was used without further purification. $p$-Toluenesulfonic acid was purified using the Dean and Stark method and benzene as the solvent.

2.1.1.Quantum Mechanics Calculations. The equilibrium molecular geometry of the ground states for dyes $\mathbf{2 a - f}$ was calculated using three different semiempirical MO parameters, AM1, PM3, and PM5. Subsequently, the ground state equilibrium molecular geometry of each dye was used in ZINDOINDO1/S [1-11] calculations to calculate the electronic transitions of dyes $\mathbf{2 a}-\mathbf{f}$ using configurational interaction (CI) of 26 occupied and 26 virtual molecular orbitals in INDO1/S with dimethylformamide solvent effect. The effect of solvent on the vertical electronic excitations was accounted for using the conductor-like screening model (COSMO), which approximates the dielectric screening energy of a solvent by the method of image charges, assuming the medium is a conductor. All calculations were performed using Scigress Workspace Version 7.7.0.47. Moreover, the ground state geometry and vertical electronic excitations were also calculated 
using DFT and TD-DFT, respectively, utilizing the energy functional B3LYP and the basis set DGTZVP (density Gauss triple- $\zeta$ with polarization functions). The DFT calculations were performed on the East Carolina University's Super Computer Jasta using 8 processors and 4 GB of RAM. All calculations were performed using Gaussian 09. The solvent effect was accounted for using the polarizable conductor calculation model (PCM), implemented in Gaussian 09.

\subsubsection{Synthesis of Porphyrin Derivatives $\mathbf{2 a - f}$}

General Procedure. A mixture of the appropriate aromatic aldehyde (1.44 mmol), pyrrole (1.44 mmol, $0.0967 \mathrm{~g})$ in DMF $(10 \mathrm{~mL})$ was placed into a $100 \mathrm{~mL}$ three necked roundbottom flask fitted with magnetic stirrer, condenser equipped with a Dean-Stark trap, thermometer and argon gas bubbler inlet tube. The reaction mixture was flushed with argon for $5 \mathrm{~min}$ and then heated to $100^{\circ} \mathrm{C}$ for $10 \mathrm{~min}$. Toluene sulfonic acid (1.44 mmol, dissolved in $5 \mathrm{~mL}$ DMF) was added to the reaction mixture using a syringe. The clear, colorless reaction mixture turned various shades of red over the next 1-2 min and was heated to $150^{\circ} \mathrm{C}$ and held at this temperature for 1h. Aliquots were removed from the reaction mixture to monitor it by UV-Vis. UV-Vis and DMF solutions showed the first product in the reaction to absorb at $504 \mathrm{~nm}$ (Qband). On continued heating at $150^{\circ} \mathrm{C}$, the Soret band of porphyrins $\left(\lambda_{\max } 415-430 \mathrm{~nm}\right)$ continued to grow with continuous decline in the $\mathrm{Q}$ band intensity. After $1 \mathrm{~h}$ at $150^{\circ} \mathrm{C}$, the reaction mixture was cooled in an ice bath for $20 \mathrm{~min}$. The mixture was then poured into ice-water. The precipitate was collected by filtration, dried under vacuum at ambient temperature, and the residue was purified by column chromatography (silica gel, chloroform/hexane: 1.5/1: eluent).

5,10,15,20-Mesotetrakis[p-methoxyphenyl]-21H,23H-porphyrin (2a). Yield $72 \%$; m.p. $180^{\circ} \mathrm{C}$; IR $(\mathrm{KBr}): v / \mathrm{cm}^{-1}=3419$ $(\mathrm{NH}), 1632(\mathrm{C}=\mathrm{N}), 1561(\mathrm{C}=\mathrm{C}) ;{ }^{1} \mathrm{H}-\mathrm{NMR}\left(\mathrm{DMSO}-d_{6}\right) \delta$ (ppm): $3.83\left(\mathrm{~s}, 12 \mathrm{H}, 4 \mathrm{OCH}_{3}\right), 4.11(\mathrm{~s}, 1 \mathrm{H}, \mathrm{NH}), 5.20(\mathrm{~d}, 2 \mathrm{H}$, 2 pyrrolic $\mathrm{CH}), 5.95$ (d, $2 \mathrm{H}, 2$ pyrrolic $\mathrm{CH}), 6.38$ (d, $2 \mathrm{H}, 2$ pyrrolic $\mathrm{CH}), 6.60$ (d, $2 \mathrm{H}, 2$ pyrrolic $\mathrm{CH}), 6.81(\mathrm{~d}, 8 \mathrm{H}, \mathrm{Ar}-\mathrm{H})$, 7.41 (d, 4H, Ar-H), 7.58 (d, 4H, Ar-H), 10.10 (s, 1H, NH); UV-Vis. spectrum: $\left(\lambda_{\max }\right), 424 \mathrm{~nm}, \log \varepsilon=4.1$. Anal. Calcd. for $\mathrm{C}_{48} \mathrm{H}_{38} \mathrm{~N}_{4} \mathrm{O}_{4}$ (734.84): C, 78.45; H, 5.21; N, 7.62\%. Found: C, 78.52; H, 5.28; N, 7.68\%.

5,10,15,20-Mesotetrakis[2,6-dichlorophenyl]-21H,23H-porphyrin $(\mathbf{2 b})$. Yield $78 \%$; m.p. $144^{\circ} \mathrm{C}$; IR $(\mathrm{KBr}): \nu / \mathrm{cm}^{-1}=3350$ $(\mathrm{NH}), \quad 1625 \quad(\mathrm{C}=\mathrm{N}), \quad 1561 \quad(\mathrm{C}=\mathrm{C}), \quad 705 \quad(\mathrm{C}-\mathrm{Cl}) ;{ }^{1} \mathrm{H}-$ NMR(DMSO- $\left.d_{6}\right) \delta(\mathrm{ppm}): 2.32(\mathrm{~s}, 1 \mathrm{H}, \mathrm{NH}), 5.20(\mathrm{~d}$, $2 \mathrm{H}, 2$ pyrrolic $\mathrm{CH}$ ), 5.89 (d, 2H, 2 pyrrolic $\mathrm{CH}), 6.19$ (d, 2H, 2 pyrrolic $\mathrm{CH}), 6.61$ (d, 2H, 2 pyrrolic $\mathrm{CH}), 7.11$ (d, $8 \mathrm{H}, \mathrm{Ar}-\mathrm{H})$, 7.41 (q, 4H, Ar-H), 11.82 (s, 1H, NH); UV-Vis. spectrum: $\left(\lambda_{\max }\right), 422 \mathrm{~nm}, \log \varepsilon=4.2$. Anal. Calcd. for $\mathrm{C}_{44} \mathrm{H}_{22} \mathrm{C}_{18} \mathrm{~N}_{4}$ (890.30): C, 59.36; H, 2.49; N, 6.29\%. Found: C, 59.45; H, $2.53 ; \mathrm{N}, 6.36 \%$.

5,10,15,20-Mesotetrakis[4-hydroxy-3,5-dimethoxyphenyl]-21H, $23 \mathrm{H}$-porphyrin (2c). Yield 75\%; m.p. $180^{\circ} \mathrm{C}$; IR (KBr): $v / \mathrm{cm}^{-1}=3419(\mathrm{OH}), 3300(\mathrm{NH}), 2983\left(\mathrm{CH}_{3}\right), 1612(\mathrm{C}=\mathrm{N})$,
$1554(\mathrm{C}=\mathrm{C}) ;{ }^{1} \mathrm{H}-\mathrm{NMR}\left(\mathrm{DMSO}-d_{6}\right) \delta$ (ppm): $3.61(\mathrm{~s}, 24 \mathrm{H}$, $\left.8 \mathrm{OCH}_{3}\right), 3.89(\mathrm{~s}, 1 \mathrm{H}, \mathrm{NH}), 5.21(\mathrm{~d}, 2 \mathrm{H}, 2$ pyrrolic $\mathrm{CH})$, 6.39 (d, 2H, 2 pyrrolic $\mathrm{CH}), 6.45$ (d, 2H, 2 pyrrolic $\mathrm{CH}$ ), 7.45 (d, 2H, 2 pyrrolic CH), 7.91 (s, 8H, Ar-H), 8.92 (s, 4H, $4 \mathrm{OH}), 10.41$ (s, $1 \mathrm{H}, \mathrm{NH})$; UV-Vis. spectrum: $\left(\lambda_{\max }\right), 430 \mathrm{~nm}$, $\log \varepsilon=4.1$. Anal. Calcd. for $\mathrm{C}_{52} \mathrm{H}_{46} \mathrm{~N}_{4} \mathrm{O}_{12}$ (918.94): C, 67.96; H, 5.05; N, 6.10\%. Found: C, 68.04; H, 5.11; N, 6.17\%.

5,10,15,20-Mesotetrakis[3,4-dimethoxyphenyl]-21H,23H-porphyrin (2d). Yield $70 \%$; m.p. $156^{\circ} \mathrm{C}$; IR (KBr): $v / \mathrm{cm}^{-1}=$ $3320(\mathrm{NH}), 2983\left(\mathrm{CH}_{3}\right), 1620(\mathrm{C}=\mathrm{N}), 1594(\mathrm{C}=\mathrm{C}), 1315$ (C-O); ${ }^{1} \mathrm{H}-\mathrm{NMR}\left(\mathrm{CDCl}_{3}\right) \delta$ (ppm): $3.86\left(\mathrm{~s}, 12 \mathrm{H}, 4 \mathrm{OCH}_{3}\right)$, $3.88\left(\mathrm{~s}, 12 \mathrm{H}, 4 \mathrm{OCH}_{3}\right), 4.21(\mathrm{~s}, 1 \mathrm{H}, \mathrm{NH}), 5.32(\mathrm{~d}, 2 \mathrm{H}, 2$ pyrrolic $\mathrm{CH}), 6.16(\mathrm{~d}, 2 \mathrm{H}, 2$ pyrrolic $\mathrm{CH}), 6.69$ (d, 2H, 2 pyrrolic $\mathrm{CH}), 6.73$ (d, 2H, 2 pyrrolic $\mathrm{CH}$ ), 7.26 (d, 4H, Ar-H), 7.91 (s, 4H, Ar-H), 8.50 (d, 4H, Ar-H), 10.28 (s, 1H, NH); UV-Vis. spectrum: $\left(\lambda_{\max }\right), 424 \mathrm{~nm}, \log \varepsilon=4.1$. Anal. Calcd. for $\mathrm{C}_{52} \mathrm{H}_{46} \mathrm{~N}_{4} \mathrm{O}_{8}$ (854.94): C, 73.05; H, 5.42; N, 6.55\%. Found: C, 73.13; H, 5.48; N, 6.63\%.

5,10,15,20-Mesotetrakis[2,4-dichlorophenyl-21H,23H-porphyrin (2e). Yield $79 \%$; m.p. $166^{\circ} \mathrm{C}$; IR $(\mathrm{KBr}): v / \mathrm{cm}^{-1}=3340$ $(\mathrm{NH}), \quad 1620 \quad(\mathrm{C}=\mathrm{N}), \quad 1594 \quad(\mathrm{C}=\mathrm{C}), \quad 740 \quad(\mathrm{C}-\mathrm{Cl}) ;{ }^{1} \mathrm{H}-$ NMR(DMSO- $\left.d_{6}\right) \delta(\mathrm{ppm}): 2.26(\mathrm{~s}, 1 \mathrm{H}, \mathrm{NH}), 3.83(\mathrm{~s}$, $1 \mathrm{H}, \mathrm{NH}), 5.37$ (d, 2H, 2 pyrrolic $\mathrm{CH}, J=12.2 \mathrm{~Hz}), 5.82(\mathrm{~d}$, $2 \mathrm{H}, 2$ pyrrolic $\mathrm{CH}, J=12.2 \mathrm{~Hz}), 6.63(\mathrm{~d}, 2 \mathrm{H}, 2$ pyrrolic $\mathrm{CH}$, $J=12.2 \mathrm{~Hz}), 6.99(\mathrm{~d}, 2 \mathrm{H}, 2$ pyrrolic $\mathrm{CH}, J=12.1 \mathrm{~Hz}), 7.34$ (d, 4H, Ar-H), 7.55 (d, 4H, Ar-H), 7.94 (s, 4H, Ar-H), 10.64 (s, 1H, NH); UV-Vis. spectrum: $\left(\lambda_{\max }\right), 420 \mathrm{~nm}, \log \varepsilon=3.9$. Anal. Calcd. for $\mathrm{C}_{44} \mathrm{H}_{22} \mathrm{C}_{18} \mathrm{~N}_{4}$ (890.30): C, 59.36; H, 2.49; N, 6.29\%. Found: C, 59.42; H, 2.56; N, 6.38\%.

5,10,15,20-Mesotetrakis[3,4,5-trimethoxyphenyl-21H,23H-pophyrin (2f). Yield 82\%; m.p. $128^{\circ} \mathrm{C}$; IR (KBr): $v / \mathrm{cm}^{-1}=3419$ $(\mathrm{OH}), 3300(\mathrm{NH}), 2983\left(\mathrm{CH}_{3}\right), 1612(\mathrm{C}=\mathrm{N}), 1554(\mathrm{C}=\mathrm{C})$; ${ }^{1} \mathrm{H}-\mathrm{NMR}\left(\mathrm{DMSO}-d_{6}\right) \delta(\mathrm{ppm}): 3.58\left(\mathrm{~s}, 24 \mathrm{H}, 8 \mathrm{OCH}_{3}\right), 3.74$ $\left(\mathrm{s}, 12 \mathrm{H}, 4 \mathrm{OCH}_{3}\right), 4.00(\mathrm{~s}, 1 \mathrm{H}, \mathrm{NH}), 5.22(\mathrm{~d}, 2 \mathrm{H}, 2$ pyrrolic $\mathrm{CH}, J=12.1 \mathrm{~Hz}), 5.61(\mathrm{~d}, 2 \mathrm{H}, 2$ pyrrolic $\mathrm{CH}, J=12.1 \mathrm{~Hz})$, 5.87 (d, 2H, 2 pyrrolic CH, $J=12.1 \mathrm{~Hz}), 6.54(\mathrm{~d}, 4 \mathrm{H}, \mathrm{Ar}-\mathrm{H})$, 6.61 (d, 4H, Ar-H), 7.91 (d, 2H, 2 pyrrolic CH), 10.44 (s, 1H, $\mathrm{NH}$ ); UV-Vis. spectrum: $\left(\lambda_{\max }\right), 424 \mathrm{~nm}, \log \varepsilon=4.1$. Anal. Calcd. for $\mathrm{C}_{56} \mathrm{H}_{54} \mathrm{~N}_{4} \mathrm{O}_{12}$ (975.05): C, 68.98; H, 5.58; N, 5.75\%. Found: C, 69.02; H, 5.64; N, 5.83\%.

\subsection{Biological Activity}

2.2.1. Reagents. DNA (Type 1. Calf Thymus), bleomycin sulfate, butylated hydroxyanisole (BHA), and L-ascorbic acid were purchased from Sigma Company. 2,2' -Azo-bis-(2amidinopropane) dihydrochloride (AAPH) and 2,2' -azinobis(3-ethyl benzthiazoline-6-sulfonic acid) (ABTS) were purchased from Wak. All other chemicals were of analytical grade.

2.2.2. Antioxidant Activity Screening Assay for Erythrocytes Haemolysis. Blood was obtained from rats by cardiac puncture and collected in heparinized tubes. Erythrocytes were separated from plasma and the buffy coat was washed three 
times with 10 volumes of $0.15 \mathrm{M} \mathrm{NaCl}$. During the last washing, the erythrocytes were centrifuged at $2500 \mathrm{rpm}$ for $10 \mathrm{~min}$. to obtain a constantly packed cell preparation. Erythrocyte haemolysis was mediated by peroxyl radicals in this assay system. A $10 \%$ suspension of erythrocytes in phosphate buffered saline pH 7.4 (PBS) was added to the same volume

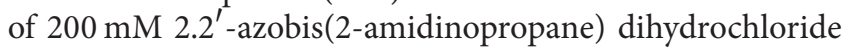
$(\mathrm{AAPH})$ solution in PBS containing samples to be tested at different concentrations. The solution was shaken gently while being incubated at $37^{\circ} \mathrm{C}$ for $2 \mathrm{~h}$, diluted with eight volumes of PBS and centrifuged at $1500 \mathrm{~g}$ for $10 \mathrm{~min}$. The absorbance (A) of the supernatant was measured at $540 \mathrm{~nm}$. Similarly, the erythrocyte solution was treated with eight volumes of distilled water to achieve complete haemolysis, and the absorbance (B) of the supernatant obtained after centrifugation was measured at $540 \mathrm{~nm}$ [27]. The percentage of haemolysis data was expressed as mean \pm standard deviation. $\mathrm{L}$-ascorbic acid was used as a positive control.

\subsubsection{Antioxidant Activity Screening Assay ABTS Method.} For each of the investigated dyes, $2 \mathrm{~mL}$ of ABTS solution $(60 \mu \mathrm{M})$ was added to $3 \mathrm{~mL} \mathrm{MnO}_{2}$ solution $(25 \mathrm{mg} / \mathrm{mL})$ all prepared in $5 \mathrm{~mL}$ aqueous phosphate buffer solution ( $\mathrm{pH} .7$, $0.1 \mathrm{M})$. The mixture was shaken, centrifuged, and filtered, and the absorbance (A control) of the resulting green-blue solution (ABTS radical solution) at $\lambda_{\max } 734 \mathrm{~nm}$ was adjusted to $\sim 0.5$. Then, $50 \mu \mathrm{L}$ of $2 \mathrm{~mL}$ solution of the test dye in spectroscopic grade $\mathrm{MeOH} /$ phosphate buffer $(1: 1)$ was added. The absorbance (A test) was measured and the reduction in color intensity was expressed as \% inhibition percentage. L. Ascorbic acid (Vitamin C) was used as standard antioxidant (Positive control), and a blank sample was run without ABTS using $\mathrm{MeOH} /$ phosphate buffer $(1: 1)$ instead of test dyes. Negative control was run with ABTS phosphate buffer $(1: 1)$ only [28].

2.2.4. Bleomycin-Dependent DNA Damage Assay. The test mixtures were contained in a final volume of $1.0 \mathrm{~mL}$, the following reagents at the concentrations indicated: DNA $(0.2 \mathrm{mg} / \mathrm{mL})$, bleomycin $(0.05 \mathrm{mg} / \mathrm{mL}), \mathrm{FeCl}_{3}(0.025 \mathrm{mM})$, $\mathrm{MgCl}_{2}$ (5 mM), $\mathrm{KH}_{2} \mathrm{PO}_{4}-\mathrm{KOH}$ buffer $\mathrm{pH} 7.0$ (30 mM), and ascorbic acid $(0.24 \mathrm{Mm})$ or the dyes tested in $\mathrm{MeOH}$ to give a concentration of $(0.1 \mathrm{mg} / \mathrm{mL})$. The test mixtures were incubated in a water-bath at $37^{\circ} \mathrm{C}$ for $1 \mathrm{~h}$. At the end of the incubation period, $0.1 \mathrm{~mL}$ of $0.1 \mathrm{M}$ EDTA was added to stop the reaction (the iron-EDTA complex is unreactive in the bleomycin assay). DNA damage was assessed by adding $1 \mathrm{~mL} 1 \%(\mathrm{w} / \mathrm{v})$ thiobarbituric acid (TBA) and $1 \mathrm{~mL} \mathrm{25 \% (v/v)}$ hydrochloric acid $(\mathrm{HCl})$ followed by heating in a water-bath maintained at $80^{\circ} \mathrm{C}$ for $15 \mathrm{~min}$. The chromogen formed was extracted into 1-butanol and the absorbance was measured at $532 \mathrm{~nm}[29,30]$.

2.2.5. Cytotoxicity and Antitumor Assay. Samples were prepared for assay by dissolving test dyes in $50 \mu \mathrm{L}$ of DMSO and diluting aliquots into sterile culture medium at $0.4 \mathrm{mg} / \mathrm{mL}$. These solutions were subdiluted to $0.02 \mathrm{mg} / \mathrm{mL}$ in sterile medium and the two solutions used as stocks to test samples at $100,50,20,10,5,2$ and $1 \mathrm{mg} / \mathrm{mL}$ in triplicate in the wells of microtiter plates.

The test dyes $\mathbf{2 a - f}$ were assayed in triplicate on monolayers grown in Dulbecco's modified Eagle's medium supplemented with $10 \%(\mathrm{v} / \mathrm{v})$ calf serum (Hyclone Laboratories, Ogden, UT), $60 \mathrm{mg} / \mathrm{mL}$ Penicillin G and $100 \mathrm{mg} / \mathrm{mL}$ streptomycin sulfate maintained at $37^{\circ} \mathrm{C}$ in a humidified atmosphere containing about $15 \%(\mathrm{v} / \mathrm{v}) \mathrm{CO}_{2}$ in air. All medium components were obtained from Sigma Chemical Co., St. Louis, $\mathrm{MO}$, unless otherwise indicated. Cells stocks were maintained at $34^{\circ} \mathrm{C}$ in culture flasks filled with medium supplemented with $1 \%(\mathrm{v} / \mathrm{v})$ calf serum. Subcultures of cells for screening were grown in the wells of microtiter trays (Falcon Microtest III 96-wells trays, Becton Dickinson Labware, Lincoln Park, NJ) by suspending cells in medium following trypsin-EDTA treatment, counting the suspension with a hemocytometer, diluting in medium containing $10 \%$ calf serum to $2 \times 10^{4}$ cells per $200 \mathrm{~mL}$ culture, aliquoting into each well of a tray, and culturing until confluent.

Microtiter trays with confluent monolayer cultures of cells were inverted, the medium was shaken out and replaced with serial dilutions of sterile dyes in triplicate in $100 \mu \mathrm{L}$ medium followed by tittered virus in $100 \mu \mathrm{L}$ medium containing $10 \%(\mathrm{v} / \mathrm{v})$ calf serum in each well. In each tray, the last row of wells was reversed for controls that were not treated with dyes. The trays were cultured for $96 \mathrm{~h}$. The trays were inverted onto a pad of paper towels, the remaining cells rinsed carefully with medium and fixed with $3.7 \%(\mathrm{v} / \mathrm{v})$ formaldehyde in saline for at least $20 \mathrm{~min}$. The fixed cells were rinsed with water and examined visually. The cytotoxic activity is identified as confluent, relatively unaltered monolayers of stained cells treated with dyes. Cytotoxicity was estimated as the concentration that caused approximately $50 \%$ loss of the monolayer. 5-Fluorouracil was used as a positive control.

\section{Results and Discussion}

3.1. Chemistry. Although numerous synthetic methodologies for porphyrin and porphyrin derivatives were reported [31, 32], we developed a new synthetic approach because of longstanding problems with low yield reactions, typically in range of 6-20\% following purification [33]. The developed synthetic method gave 95-98\% yield with minimal chromatography. The key to our success was a capping mechanism using DMF as a solvent, to prevent the formation of polymeric pyrrole.

Meso-porphyrin derivatives $\mathbf{2 a - f}$ were synthesized from the condensation of aldehyde derivatives $\mathbf{1 a}-\mathbf{f}$ with pyrrole in presence of $p$-toluenesulfonic acid as shown in Scheme 1. The mechanism for porphyrin formation involves acid-catalyzed addition of pyrrole to the substituted benzaldehyde carbonyl group followed by acid-catalyzed dehydration. Repeating this process adds a second benzaldehyde moiety. Ring closure results in the formation of the reduced form of porphyrin (porphyrinogen) followed by oxidation to furnish the porphyrin building blocks. The proposed capping mechanism is shown in Scheme 2, we believe that in the presence of DMF, a reversible cap forms that protects this intermediate species, while allowing the reaction with pyrrole. If DMF or another 


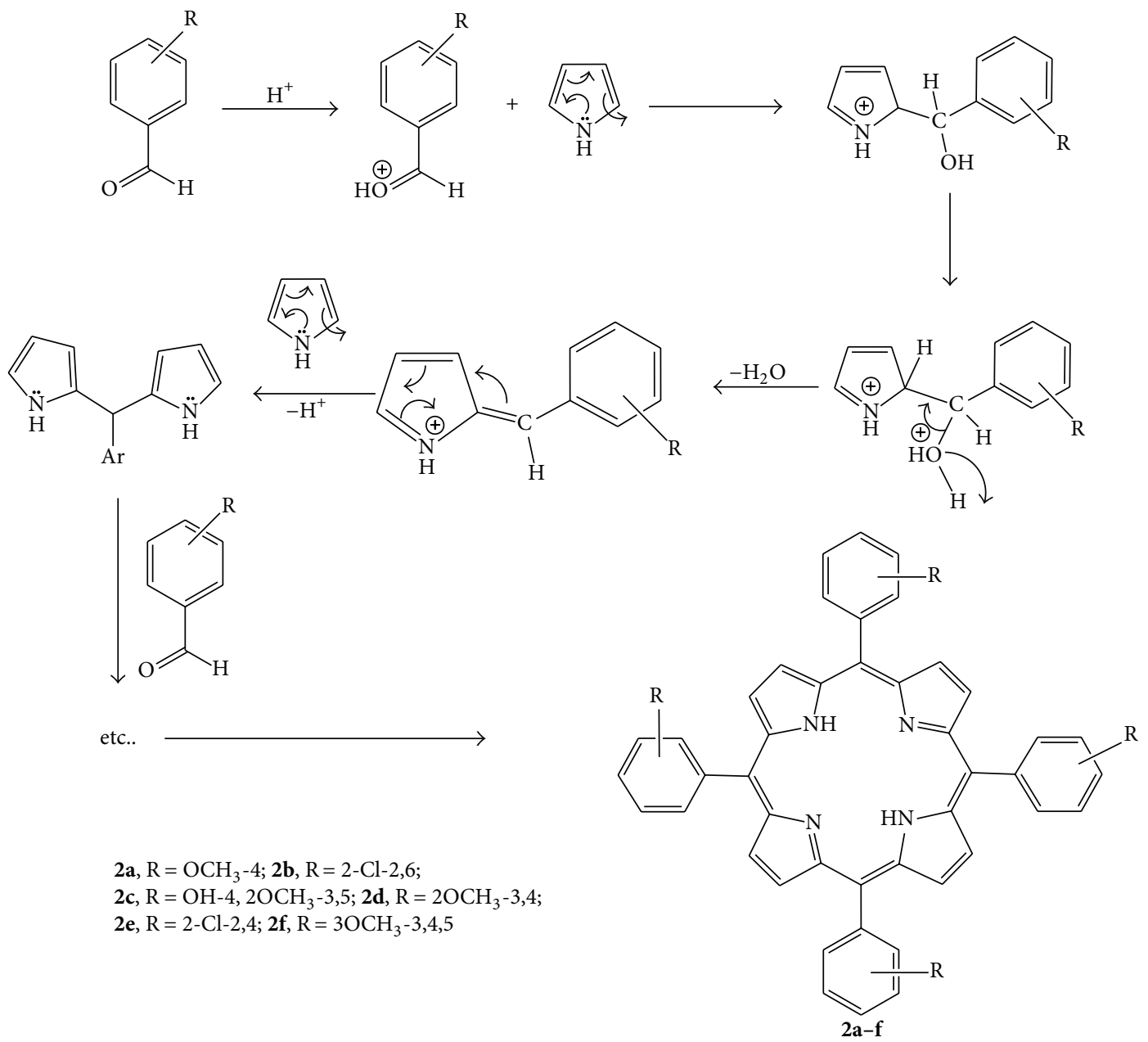

SCHEME 1: Conventional synthetic route for the preparation of porphyrin derivatives $2 \mathbf{a}-\mathbf{f}$.

solvent that can cap the reactive intermediate is not used as the solvent, this intermediate may react by polymerizing to generate a tarry substance or intractable mixture.

The DMF capped reactive species reacts with more pyrrole to continue to furnish the corresponding porphyrinogen, and the DMF molecule would act as a good leaving group in each case pyrrole is added.

3.2. Calculated Equilibrium Molecular Geometry, Ground, and Excited Electronic States. The equilibrium molecular geometry of dyes $\mathbf{2 a - f}$ were predicted using quantum mechanics methods AM1, PM3, PM5, and DFT to identify the method that would furnish the most accurate equilibrium geometry in the ground state. The optimized torsion angles $(\boldsymbol{\theta 1}-\boldsymbol{\theta 4})$, singlet electronic transitions corresponding to the $\lambda_{\max }$ for each dye are presented in Table 1. A noticeable difference in the torsion angles calculated using semiempirical $\mathrm{MO}$ methods versus the DFT method was observed. It was found that the calculated $\lambda_{\max }$ using the TD-DFT method was in excellent agreement with the experimental results while the semiempirical MO methods were inferior. This indicates that the equilibrium molecular geometries calculated using DFT for dyes $\mathbf{2 a - f}$ were more accurate than those calculated using AM1, PM3 or PM5 parameters.

Figure 1(a) shows the optimized molecular geometry calculated in vacuum for compound $\mathbf{2 a}$ as an example showing its torsion angles $\boldsymbol{\theta 1 - \boldsymbol { \theta 4 }}$, shown in bold, predicted using AM1, in the range of $61.45-64.27^{\circ}$. The angles $\boldsymbol{\theta 1 -}$ $\boldsymbol{\theta} 4$ represent the torsion angles between the aryl at the meso-position and porphyrin moiety. As shown in Table 1, it should be noted that $\boldsymbol{\theta 1 - \boldsymbol { \theta }}$ varied based on the type and position of substituents attached to the aryl synthon, which ultimately influenced $\lambda_{\max }$ of the Soret band. For example, compound $\mathbf{2} \mathbf{b}$, where the meso-position is occupied by 2,4 dichlorophenyl, the $\boldsymbol{\theta 1 - \boldsymbol { \theta } 4}$ was in the range of 89.25-90.06. The reason the torsion angles are more twisted in dye $\mathbf{2 b}$ compared to dye $\mathbf{2} \mathbf{a}$ is the presence of a substituent at position 2 (ortho) on the phenyl ring, which increases the twist across the phenyl-porphyrin linkage even further. The increase in the twist in $(\boldsymbol{\theta 1}-\boldsymbol{\theta} 4)$ further precludes the coplanarity of substituted aryls at the meso-positions, diminishing the orbitals overlap between the aryl groups at the meso-positions and porphyrin moiety, which translated into a hypsochromic 

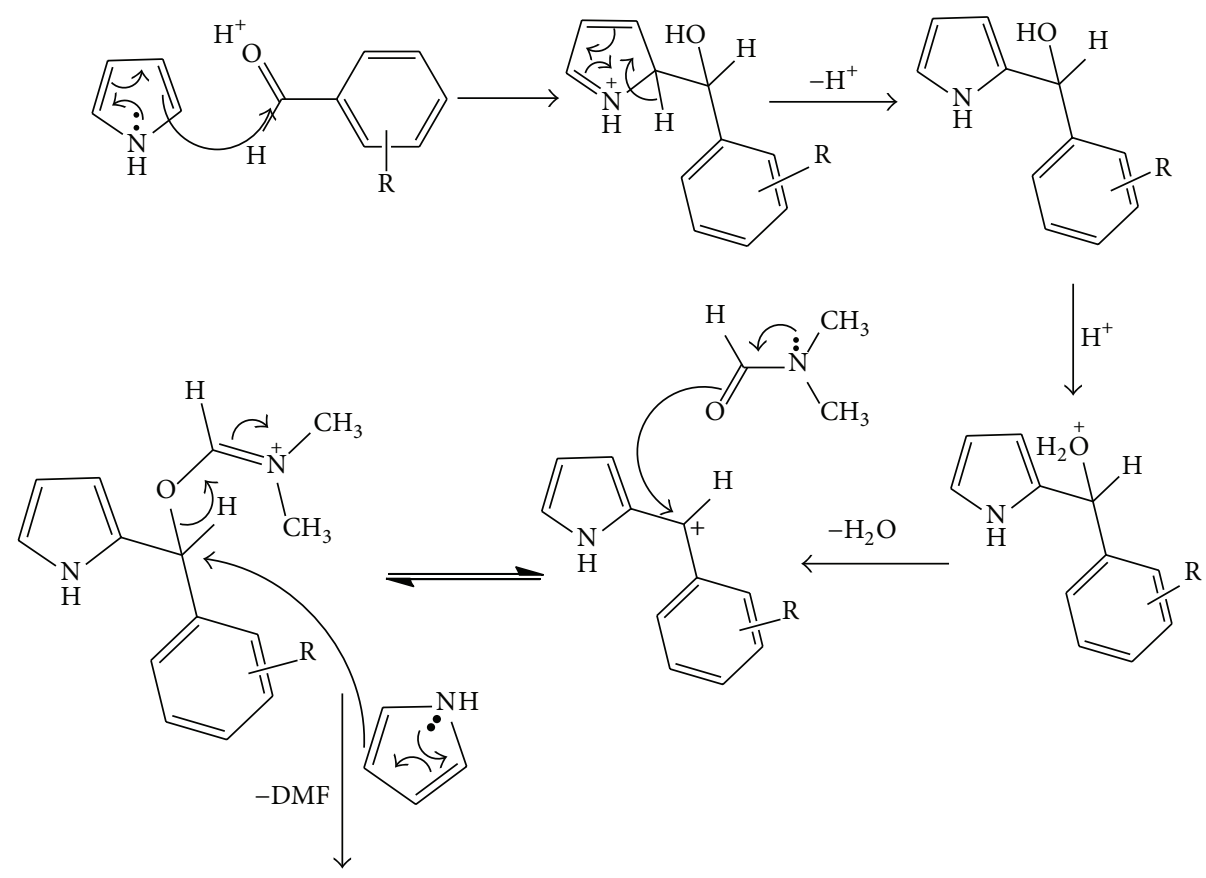<smiles>[R]c1ccccc1C(c1ccc[nH]1)c1ccc[nH]1</smiles>

Scheme 2: Proposed role of DMF as a capping agent during porphyrin formation.

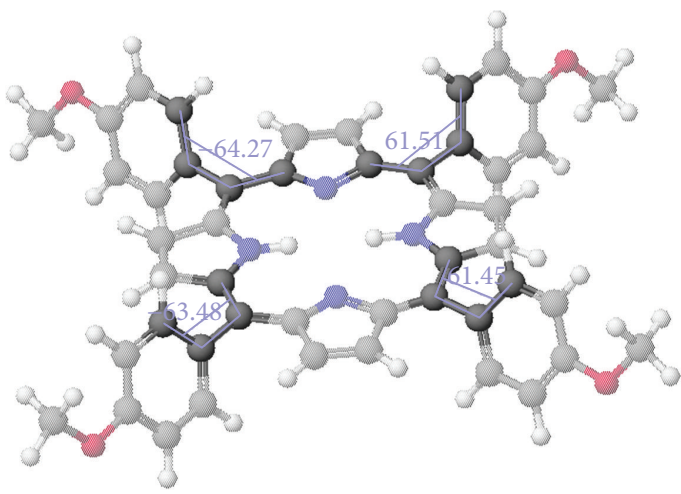

(a)

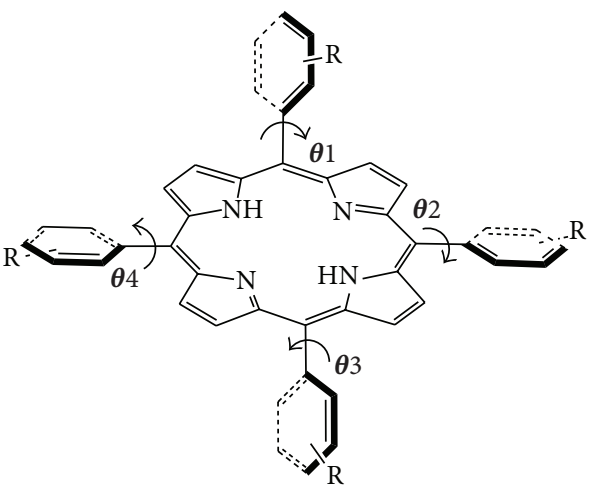

(b)

FIGURE 1: (a) Equilibrium molecular geometry of dye 2a using AM1 parameters, and (b) a general structure of dyes $2 \mathbf{a}-\mathbf{f}$ showing the locations of torsion angles $\boldsymbol{\theta 1 - \theta 4}$.

shift compared to porphyrin carrying aryl groups at the mesopositions with less twisted torsion angles.

To gain more insights and better understanding of the correlation between the molecular structures of dyes $2 \mathbf{a}-\mathbf{f}$ and their biological activity, different molecular descriptors including HOMO, LUMO, and HOMO-LUMO gap energies and dipole moment were calculated using TD-DFT calculations using the energy functional B3LYP and the basis set DGTZVP, shown in Table 2. Excellent correlation between the LUMO energy and the cytotoxicity of dyes $2 \mathbf{a}-\mathbf{f}$ was found-the higher the LUMO energy (Figure 2), the higher the cytotoxic activity. Hence, LUMO energy can be used in 


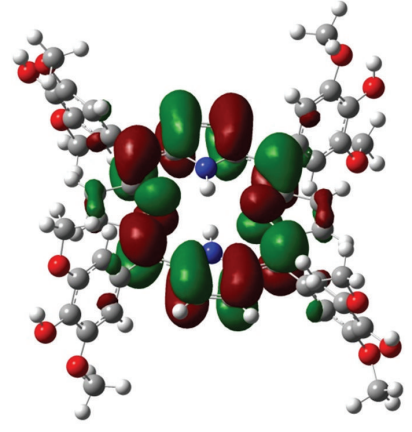

(a)

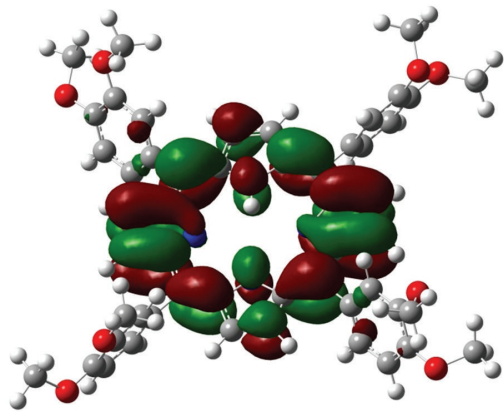

(d)

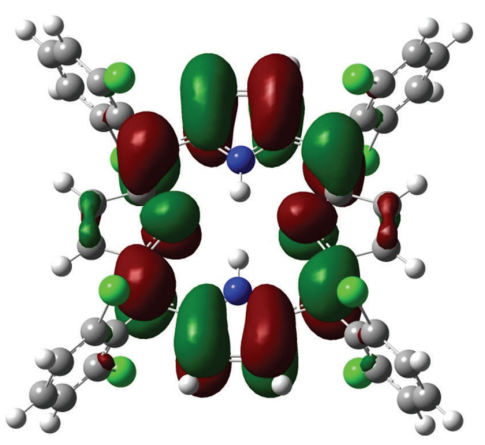

(b)

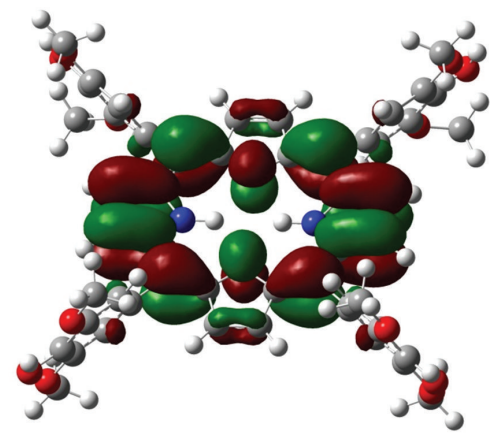

(c)

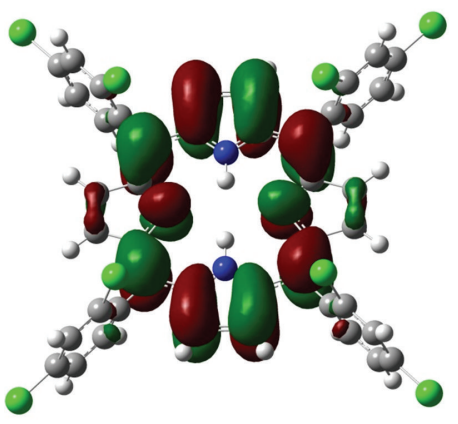

(e)

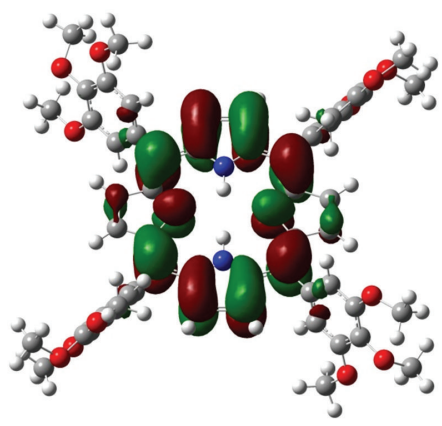

(f)

FIGURE 2: LUMO plots of dye 2a-f calculated using the energy functional B3LYP.

TABle 1: Photophysical properties of dyes $\mathbf{2 a - f}$.

\begin{tabular}{lccccccccc}
\hline Dye & \multicolumn{3}{c}{$\begin{array}{c}\lambda_{\max }(\mathrm{nm}) \\
\text { Calculated }\end{array}$} & & Expt. & DFT/B3LYP & Optimized geometry calculated $\boldsymbol{\theta 1 - \theta 4}$ & AM1 & PM3 \\
\hline & AM1 & PM3 & PM5 & TD-DFT & & & & \\
2a & 383 & 373 & 375 & 421 & 424 & $69.02-69.21$ & $61.45-64.27$ & $83.37-88.24$ & $52.56-70.13$ \\
2b & 374 & 370 & 367 & 414 & 422 & $89.95-89.95$ & $89.97-90.86$ & $89.65-90.72$ & $88.61-91.79$ \\
2c & 382 & 373 & 374 & 427 & 430 & $68.28-69.21$ & $62.10-64.64$ & $81.85-88.59$ & $63.18-68.53$ \\
2d & 395 & 427 & 383 & 426 & 424 & $69.10-70.01$ & $10.66-75.38$ & $19.01-86.23$ & $53.44-60.68$ \\
2e & 373 & 372 & 367 & 413 & 420 & $88.51-88.57$ & $89.25-90.06$ & $89.46-89.57$ & $87.52-88.70$ \\
2f & 382 & 373 & 374 & 434 & 424 & $69.71-71.46$ & $62.47-64.94$ & $82.04-90.32$ & $63.67-69.29$ \\
\hline
\end{tabular}

TABLE 2: Calculated HOMO, LUMO, and HOMO-LUMO gap energy and dipole moment of dyes 2a-f.

\begin{tabular}{lcccc}
\hline Dyes & HOMO $(\mathrm{eV})$ & LUMO $(\mathrm{eV})$ & HOMO-LUMO gap (eV) & Dipole moment (debye) \\
\hline $\mathbf{2 a}$ & -5.468 & -2.7976 & 2.670 & 0.00 \\
$\mathbf{2 b}$ & -5.873 & -3.0346 & 2.838 & 0.00 \\
$\mathbf{2 c}$ & -5.467 & -2.8054 & 2.661 & 8.33 \\
$\mathbf{2 d}$ & -5.542 & -2.8327 & 2.709 & 5.68 \\
$\mathbf{2 e}$ & -5.848 & -3.0082 & 2.839 & 5.05 \\
$\mathbf{2 f}$ & -5.541 & -2.8120 & 2.729 & 2.64 \\
\hline
\end{tabular}

the design of more efficient porphyrins for cytotoxic activity. However, no correlation was found between the calculated molecular descriptors and DNA damage or antioxidant activity.

3.3. Experimental Electronic Excited State. The electronic absorption spectra of tetra porphyrins $(\mathbf{2 a - f})$ is characterized by a strong single band in the high-energy region of the visible spectrum ranging (400-440 $\mathrm{nm}$ ), referred to as the Soret or B band and a series of bands appearing in the low-energy visible region (500-700 $\mathrm{nm}$ ), which are identified as the Q bands (Figures 3, 4 and 5). Both of these spectral features arise from $\pi-\pi^{*}$ transitions and are described by the Gouterman fourorbital model [34]. 


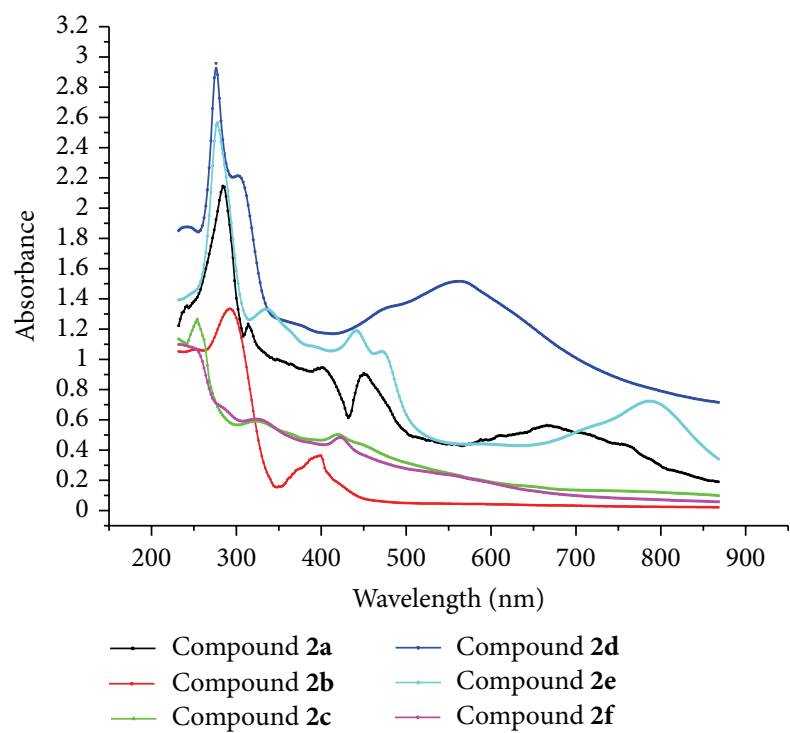

FIgURE 3: UV-Vis absorption spectra of dyes $2 \mathbf{a}-\mathbf{f}$ after $1 \mathrm{~min}$ reaction time.

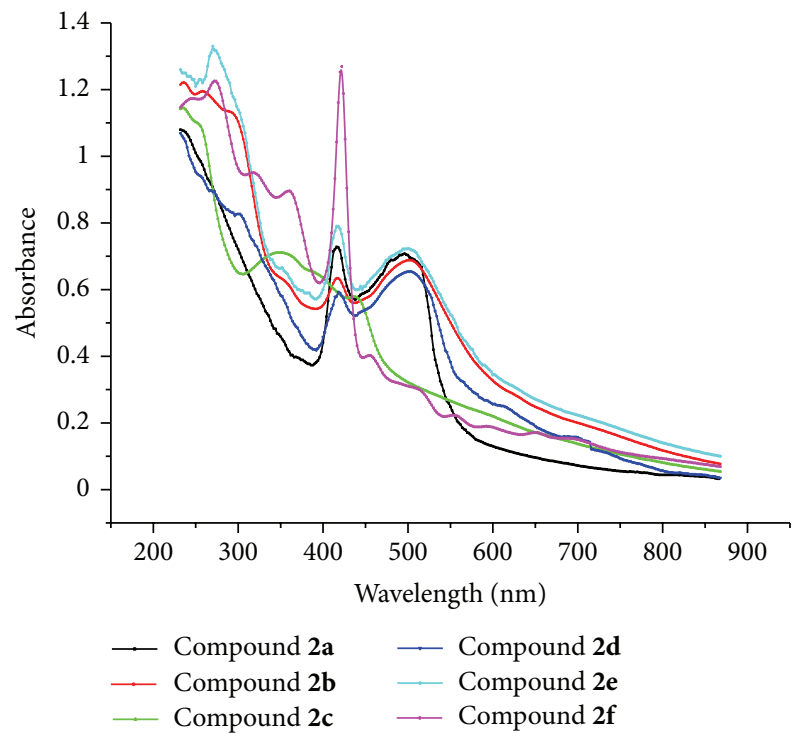

Figure 4: UV-Vis Absorption spectra of dyes 2a-f after $30 \mathrm{~min}$ reaction time.

Considerable changes in the $\lambda_{\max }$ of dyes $2 \mathbf{a}-\mathbf{f}$ were not observed upon the incorporation of ring deactivating and activating groups. This lack of electronic spectral modulation is due to the significant twist of the torsion angles resulting from steric interactions of the ortho-aryl and $\beta$-pyrrole hydrogens furnishing weak $\pi$-overlap between the porphyrin ring and peripheral aryls.

In their ${ }^{1} \mathrm{H}$ NMR spectra, porphyrin derivatives $\mathbf{2 a - 2 f}$ exhibit two sets of doublets for the pyrrolic $\mathrm{C}-\mathrm{H}$ protons, typically between $\delta 5.0$ and $7.0 \mathrm{ppm}$, in sharp contrast to the signals for porphyrins normally found above $\delta 8 \mathrm{ppm}$. This

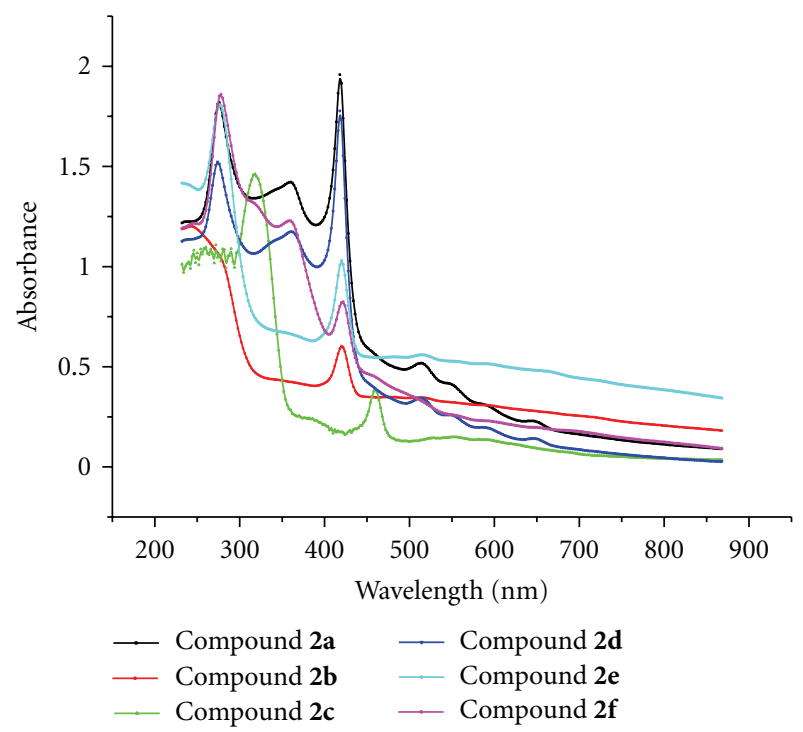

FIGURE 5: UV-Vis Absorption spectra of dyes 2a-f after $h$ reaction time.

TABle 3: Results of bleomycin-dependent DNA damage assay on dyes $\mathbf{2 a - 2 f}$.

\begin{tabular}{lc}
\hline Dye number & Absorbance \\
\hline 2a & 0.050 \\
2b & 0.007 \\
2c & 0.033 \\
2d & 0.006 \\
2e & 0.400 \\
2f & 0.004 \\
L-ascorbic acid & 0.0038 \\
\hline
\end{tabular}

TABLE 4: Results of antioxidant assay on dyes $\mathbf{2 a - 2 f}$.

\begin{tabular}{lcc}
\hline Dye number & ABTS Inhibition (\%) & Erythrocyte Haemolysis (\%) \\
\hline 2a & 68.73 & 0.91 \\
2b & 60.18 & 0.90 \\
2c & 64.27 & 0.78 \\
2d & 74.38 & 0.89 \\
2e & 54.28 & 1.2 \\
2f & 79.46 & 0.86 \\
L-ascorbic acid & 88.61 & 0.85 \\
\hline
\end{tabular}

behavior may be attributed to the disruption of electron delocalization within the macrocycle, increasing the shielding of the pyrrolic protons.

\subsection{Pharmacology}

3.4.1. Bleomycin-Dependent DNA Damage. The bleomycins are a family of antitumor antibiotics that are used routinely as antitumor agents. The bleomycin assay has been adopted for assessing the prooxidant effects of food antioxidants. Bleomycin binds iron ions and DNA, and the resultant bleomycin-iron complex upon heating with thiobarbituric 
TABle 5: Cytotoxicity $\left(\mathrm{IC}_{50}\right)$ of tested dyes on different cell lines.

\begin{tabular}{lcccc}
\hline Dye number & & & IC $_{50}$ & VERO \\
\hline 2a & HePG2 & WI-38 & 74 & MCF-7 \\
2b & 60 & 59 & 60 & 54 \\
2c & 80 & 70 & 51 & 39 \\
2d & 66 & 100 & 42 & 36 \\
2e & 76 & 64 & 56 & 60 \\
2f & 79 & 68 & 33 & 27 \\
5-Flu. & 63 & 58 & 7 & zero \\
\hline
\end{tabular}

(IC ${ }_{50},(\mu \mathrm{g} / \mathrm{mL}): 1-10$ (very strong), 11-25 (strong), 26-50 (moderate), 51-100 (weak), 100-200 (very weak), above 200 (noncytotoxic)).

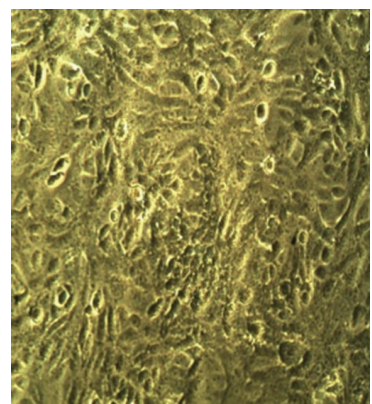

Vero cells

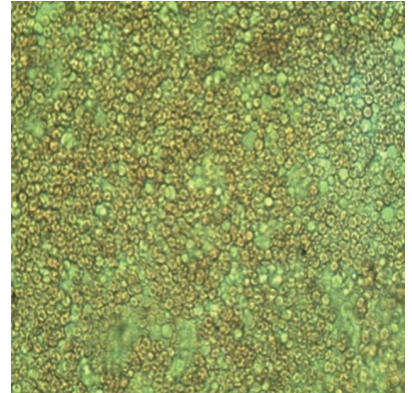

WI-38

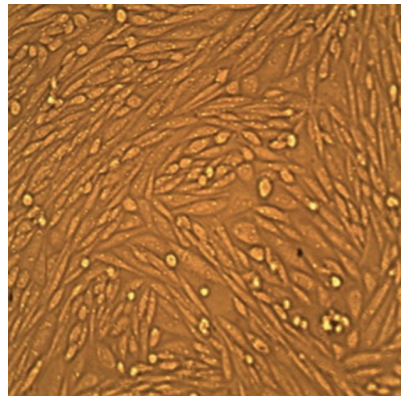

HEPG-2

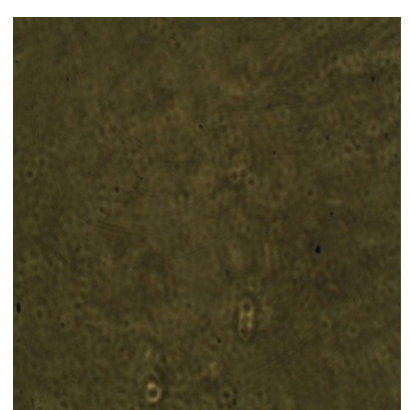

MCF-7

FIGURE 6: Confluent monolayers of cell lines used for testing.

acid, yields a pink chromogen. The additions of suitable reducing agents (antioxidants) compete with DNA and diminish chromogen formation.

Among the tested dyes (Table 3), 2b, 2d, and $\mathbf{2} \mathbf{f}$ showed the highest protection against DNA damage induced by bleomycin-iron complex, thus diminishing chromogen formation between the damaged DNA and TBA. However, dyes $\mathbf{2 a}$ and $2 \mathbf{c}$ showed a weak to moderate protection, while dye $2 \mathrm{e}$ exhibited a very low activity. In this assay, the potential for DNA damage is considered low when the intensity (absorbance value) of the pink chromogen is low.

3.4.2. Antioxidant Activity Using ABTS Inhibition and Erythrocyte Haemolysis. All dyes were tested for antioxidant activity as reflected in the ability to inhibit peroxidation in rat brain and kidney homogenates and rat erythrocyte haemolysis. The oxidant activities of the dyes were assayed for their antioxidant effects using ABTS assay. As indicated by Table 4 results, dyes $\mathbf{2 d}$ and $\mathbf{2 f}$ exhibited antioxidative activity, giving \% inhibition and erythrocyte haemolysis values similar to the prototype Vitamin C (L-ascorbic acid). On the other hand, dyes $\mathbf{2 a}, \mathbf{2} \mathbf{b}$, and $\mathbf{2} \mathbf{c}$ showed moderate activity, while dye 2 e showed weak activity.

3.4.3. Cytotoxicity. Dyes $\mathbf{2 a - 2 f}$ were tested for cytotoxic activity (Table 5) against Vero African green monkey cells, WI-38 (fibroblast cells), HepG2 (Hepatoma cells), MCF-7: cells from breast cancer (Figure 6). Dye 2a gave the best cytotoxic activity against HepG2 cell lines, whereas dyes $\mathbf{2 c}$ and $\mathbf{2} \mathbf{f}$ gave moderate cytotoxic activity against HepG2 cell lines. By comparing these dyes with 2a we noted that introducing more than one methoxy group reduced cytotoxic activity and also presence of phenolic $\mathrm{OH}$ group in dye $2 \mathrm{c}$ reduced activity compared to dye $\mathbf{2} \mathbf{f}$. Finally, dyes $\mathbf{2 b}, \mathbf{2 d}$, and 2e exhibited the lowest activity against HepG2 cells lines.

Methoxy-substituted dye $\mathbf{2} \mathbf{a}$ and $\mathbf{2} \mathbf{f}$ gave the best cytotoxic activity against WI-38 cell lines whereas dyes $\mathbf{2 b}, \mathbf{2 d}$, and 2e gave moderate cytotoxic activity against WI-38 cell lines. By comparing the structures of dyes $\mathbf{2 b}$ and $\mathbf{2 d}$ with $\mathbf{2 e}$, we noted that introducing more than one methoxy group increase cytotoxic activity. Finally, dye 2c exhibited the lowest activity against WI-38 cells lines.

Increasing the number of electron donating groups led to increasing cytotoxic activity against VERO cell lines, causing dyes $\mathbf{2} \mathbf{d}$ and $\mathbf{2} \mathbf{f}$ show the best cytotoxic activity against VERO cell lines, whereas dyes $\mathbf{2 c}$ and $\mathbf{2 e}$ exhibit moderate cytotoxic activity. Dyes $\mathbf{2 a}$ and $\mathbf{2 b}$ exhibited the lowest cytotoxic activities against VERO cell lines. Furthermore, increasing number of electron donating groups led to increased cytotoxic activity against MCF-7 cell lines, causing $2 \mathbf{c}, \mathbf{2 d}$, and $\mathbf{2 f}$ to have the best cytotoxic activity against MCF-7 cell lines, whereas 2b exhibited moderate cytotoxic activity against MCF-7 cell lines, and $\mathbf{2} \mathbf{a}$ and $\mathbf{2 e}$ exhibited the lowest cytotoxic activity against MCF-7 cell lines.

\section{Conclusions}

Although the six porphyrin derivatives $\mathbf{2 a - f}$ are not novel, they were synthesized via a new method, the capping mechanism, which led to significantly high-yield porphyrins, and 
these dyes were screened for antioxidant and antitumor activity in which dyes $\mathbf{2} \mathbf{d}$ and $\mathbf{2} \mathbf{f}$ which bears methoxy functionality exhibited markedly higher anti-haemolysis activity than the other analogs.

Further in vivo studies are warranted to confirm the biological activity of these synthesized porphyrin dyes and to investigate the molecular mechanisms responsible for the antitumor activity for these dyes with a potential pharmaceutical use. In addition, different molecular modeling methods were studied to identify the most accurate method in the prediction of the equilibrium molecular geometry and electronic properties, and it was shown that the TD-DFT method was in excellent agreement with the experimental results. Moreover, it was found that the higher the LUMO energy the stronger the cytotoxicity. Hence, LUMOs energy can be used as a molecular descriptor in the design of more efficient porphyrins for cytotoxicity.

\section{Acknowledgment}

Authors thank Professor Farid A. Badria, Professor of Pharmacognosy, Faculty of Pharmacy, Mansoura University, for biological activity screening of the tested dyes.

\section{References}

[1] J. S. Lindsey, "Synthesis of meso-substitutedporphyrins," in The Porphyrin Handbook, K. M. Kanish, K. M. Smith, and R. Guilard, Eds., vol. 1, pp. 45-118, Academic Press, San Diego, Calif, USA, 2000.

[2] D. Holten, D. F. Bocian, and J. S. Lindsey, "Probing electronic communication in covalently linked multiporphyrin arrays. A guide to the rational design of molecular photonic devices," Accounts of Chemical Research, vol. 35, pp. 57-69, 2002.

[3] A. Nakano, A. Osuka, I. Yamazaki, T. Yamazaki, and Y. Nishimura, "Synthesis of windmill-type porphyrin arrays as a potent photosynthetic antenna," Angewandte Chemie, vol. 37, pp. 3023-3027, 1998.

[4] O. Mongin, A. Schuwey, M. A. Vallot, and A. Gossauer, "Synthesis of a macrocyclic porphyrin hexamer with a nanometersized cavity as a model for the light-harvesting arrays of purple bacteria," Tetrahedron Letters, vol. 40, no. 48, pp. 8347-8350, 1999.

[5] Z. Yao, J. Bhaumik, S. Dhanalekshmi, M. Ptaszek, P. A. Rodriguez, and J. S. Lindsey, "Synthesis of porphyrins bearing 1-4 hydroxymethyl groups and other one-carbon oxygenic substituents in distinct patterns," Tetrahedron, vol. 63, no. 43, pp. 10657-10670, 2007.

[6] J. Bhaumik, Z. Yao, K. E. Borbas, M. Taniguchi, and J. S. Lindsey, "Masked imidazolyl-dipyrromethanes in the synthesis of imidazole-substituted porphyrins," Journal of Organic Chemistry, vol. 71, no. 23, pp. 8807-8817, 2006.

[7] K. Padmaja, W. J. Youngblood, L. Wei, D. F. Bocian, and J. S. Lindsey, "Triple-decker sandwich compounds bearing compact triallyl tripods for molecular information storage applications," Inorganic Chemistry, vol. 45, no. 14, pp. 5479-5492, 2006.

[8] K. Muthukumaran, R. S. Loewe, A. Ambroise et al., "Porphyrins bearing arylphosphonic acid tethers for attachment to oxide surfaces," Journal of Organic Chemistry, vol. 69, no. 5, pp. 14441452, 2004.
[9] A. Balakumar, A. B. Lysenko, C. Carcel et al., "Diverse redoxactive molecules bearing O-, S-, or Se-terminated tethers for attachment to silicon in studies of molecular information storage," Journal of Organic Chemistry, vol. 69, no. 5, pp. 14351443, 2004.

[10] L. Wei, K. Padmaja, W. J. Youngblood, A. B. Lysenko, J. S. Lindsey, and D. F. Bocian, "Diverse redox-active molecules bearing identical thiol-terminated tripodal tethers for studies of molecular information storage," Journal of Organic Chemistry, vol. 69, no. 5, pp. 1461-1469, 2004.

[11] W. M. Pardridge, "Blood-brain barrier methodology and biology," in Introduction to the Blood-Brain Barrier, W. M. Pardridge, Ed., pp. 1-8, Cambridge University Press, Cambridge, UK, 1998.

[12] J. S. Lindsey, K. A. MacCrum, J. S. Tyhonas, and Y. Y. Chuang, "Investigation of a synthesis of meso-porphyrins employing high concentration conditions and an electron transport chain for aerobic oxidation," Journal of Organic Chemistry, vol. 59, no. 3, pp. 579-587, 1994.

[13] P. Rothemund and A. R. Menotti, "Porphyrin studies. IV. 1. The synthesis of $\alpha, \beta, \gamma, \delta$-tetraphenylporphine," Journal of American Chemical Society, vol. 63, pp. 267-270, 1941.

[14] A. D. Adler, F. R. Longo, J. D. Finarelli, J. Goldmacher, J. Assour, and L. Korsakoff, "A simplified synthesis for mesotetraphenylporphin," Journal of Organic Chemistry, vol. 32, no. 2, p. $476,1967$.

[15] K. J. Barnham, C. L. Masters, and A. I. Bush, "Neurodegenerative diseases and oxidatives stress," Nature Reviews Drug Discovery, vol. 3, no. 3, pp. 205-214, 2004.

[16] M. S. Cooke, M. D. Evans, M. Dizdaroglu, and J. Lunec, "Oxidative DNA damage: mechanisms, mutation, and disease," FASEB Journal, vol. 17, no. 10, pp. 1195-1214, 2003.

[17] T. Finkel and N. J. Holbrook, "Oxidants, oxidative stress and the biology of ageing," Nature, vol. 408, no. 6809, pp. 239-247, 2000.

[18] S. P. Hussain, L. J. Hofseth, and C. C. Harris, "Radical causes of cancer," Nature Reviews Cancer, vol. 3, no. 4, pp. 276-285, 2003.

[19] Y.-J. Cai, L. P. Ma, L. F. Hou, B. Zhou, L. Yang, and Z. L. Liu, "Antioxidant effects of green tea polyphenols on free radical initiated peroxidation of rat liver microsomes," Chemistry and Physics of Lipids, vol. 120, no. 1-2, pp. 109-117, 2002.

[20] Z. H. Chen, B. Zhou, L. Yang, L. M. Wu, and Z. L. Liu, "Antioxidant activity of green tea polyphenols against lipid peroxidation initiated by lipid-soluble radicals in micelles," Journal of the Chemical Society, Perkin Transactions 2, no. 9, pp. 1835-1839, 2001.

[21] B. Zhou, Q. Miao, L. Yang, and Z. L. Liu, "Antioxidative effects of flavonols and their glycosides against the free-radical-induced peroxidation of linoleic acid in solution and in micelles," Chemistry, vol. 11, no. 2, pp. 680-691, 2005.

[22] B. Zhou, L.-M. Wu, L. Yang, and Z.-L. Liu, "Evidence for $\alpha$ tocopherol regeneration reaction of green tea polyphenols in SDS micelles," Free Radical Biology and Medicine, vol. 38, no. 1, pp. 78-84, 2005.

[23] Y. J. Cai, J. G. Fang, L. P. Ma, L. Yang, and Z.-L. Liu, "Inhibition of free radical-induced peroxidation of rat liver microsomes by resveratrol and its analogues," Biochimica et Biophysica Acta, vol. 1637, no. 1, pp. 31-38, 2003.

[24] Y.-J. Cai, Q. Y. Wei, J. G. Fang et al., “The 3,4-dihydroxyl groups are important for trans-resveratrol analogs to exhibit enhanced antioxidant and apoptotic activities," Anticancer Research, vol. 24, no. 2, pp. 999-1002, 2004. 
[25] L. Hou, B. Zhou, L. Yang, and Z.-L. Liu, "Inhibition of human low density lipoprotein oxidation by flavonols and their glycosides," Chemistry and Physics of Lipids, vol. 129, no. 2, pp. 209219, 2004.

[26] L. Hou, B. Zhou, L. Yang, and Z.-L. Liu, "Inhibition of free radical initiated peroxidation of human erythrocyte ghosts by flavonols and their glycosides," Organic and Biomolecular Chemistry, vol. 2, no. 9, pp. 1419-1423, 2004.

[27] Y. Morimoto, K. Tanaka, Y. Iwakiri, S. Tokuhiro, S. Fukushima, and Y. Takeuchi, "Protective effects of some neutral amino acids against hypotonic hemolysis," Biological and Pharmaceutical Bulletin, vol. 18, no. 10, pp. 1417-1422, 1995.

[28] A. B. A. El-Gazzar, M. M. Youssef, A. M. S. Youssef, A. A. AbuHashem, and F. A. Badria, "Design and synthesis of azolopyrimidoquinolines, pyrimidoquinazolines as anti-oxidant, antiinflammatory and analgesic activities," European Journal of Medicinal Chemistry, vol. 44, no. 2, pp. 609-624, 2009.

[29] J. M. C. Gutteridge, D. A. Rowley, and B. Halliwell, "Superoxidedependent formation of hydroxyl radicals in the presence of iron salts," Biochemical Journal, vol. 199, no. 1, pp. 263-265, 1981.

[30] B. F. Abdel-Wahab, A. A. S. El-Ahl, and F. A. Badria, "Synthesis of new 2-naphthyl ethers and their protective activities against DNA damage induced by bleomycin-iron," Chemical and Pharmaceutical Bulletin, vol. 57, no. 12, pp. 1348-1351, 2009.

[31] H. Tang, Z. Dong, Z. Merican et al., "Hinged bis-porphyrin scaffolds I. The synthesis of a new porphyrin diene and its role in constructing hinged porphyrin dyads and cavity systems," Tetrahedron Letters, vol. 50, no. 6, pp. 667-670, 2009.

[32] S. Rai and M. Ravikanth, "Synthesis of covalently linked unsymmetrical porphyrin pentads containing three different porphyrin subunits," Journal of Organic Chemistry, vol. 73, no. 21, pp. 8364-8375, 2008.

[33] C.-S. Chan, A. K. S. Tse, and K. S. Chan, "Highly versatile methods for the synthesis of quinonylporphyrins via benzannulation of Fischer carbene complexes and palladium-catalyzed crosscoupling reactions," Journal of Organic Chemistry, vol. 59, no. 20, pp. 6084-6089, 1994.

[34] M. Gouterman, "Optical spectra and electronic structure of porphyrins and related rings," in The Porphyrins, D. Dolghin, Ed., vol. 3, pp. 1-165, Academic press, New York, NY, USA, 1978. 

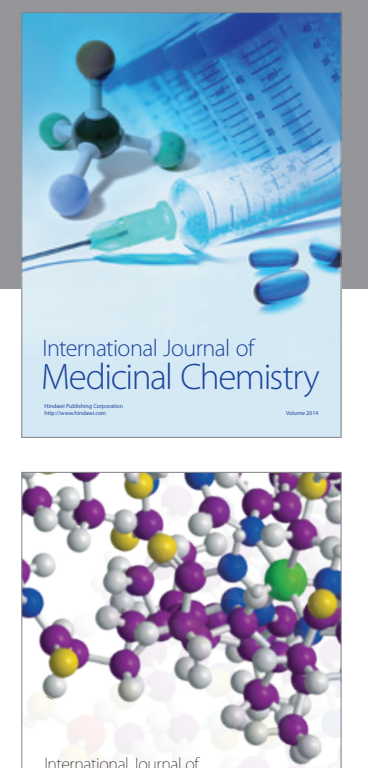

\section{Carbohydrate} Chemistry

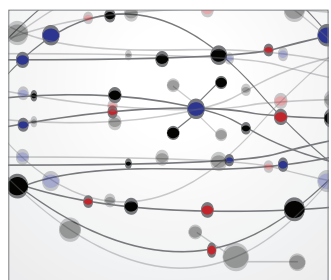

The Scientific World Journal
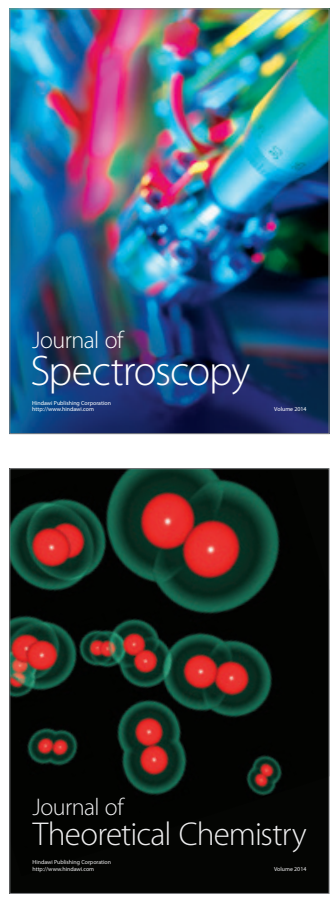
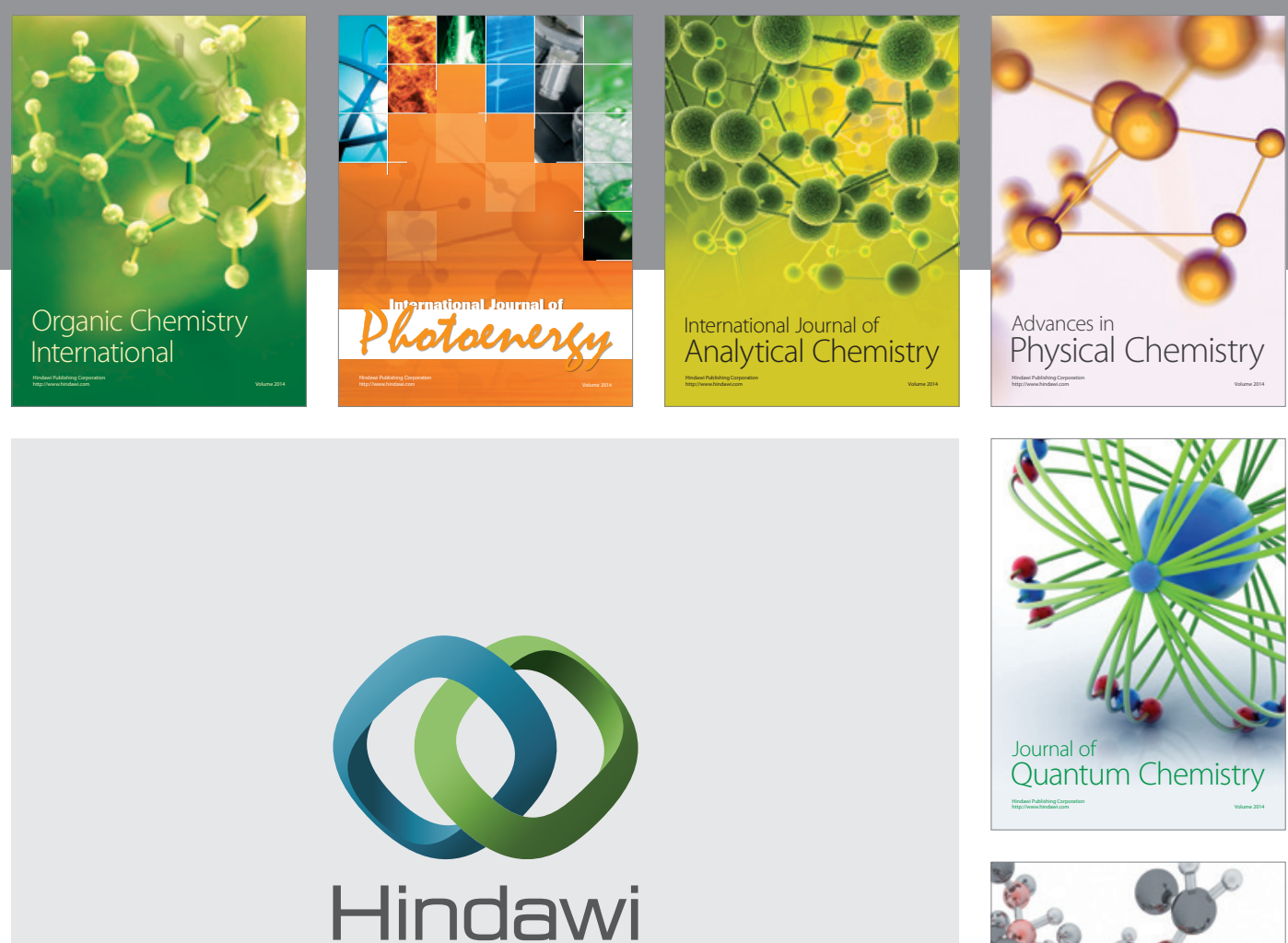

Submit your manuscripts at

http://www.hindawi.com

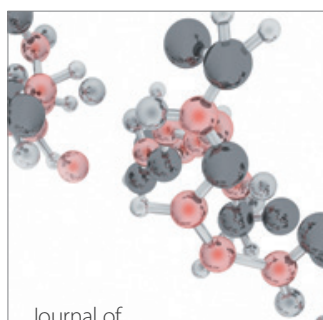

Analytical Methods

in Chemistry

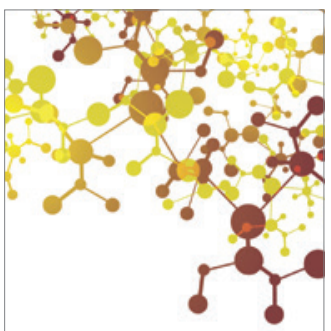

Journal of

Applied Chemistry

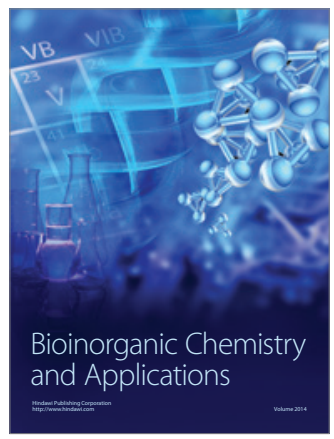

Inorganic Chemistry
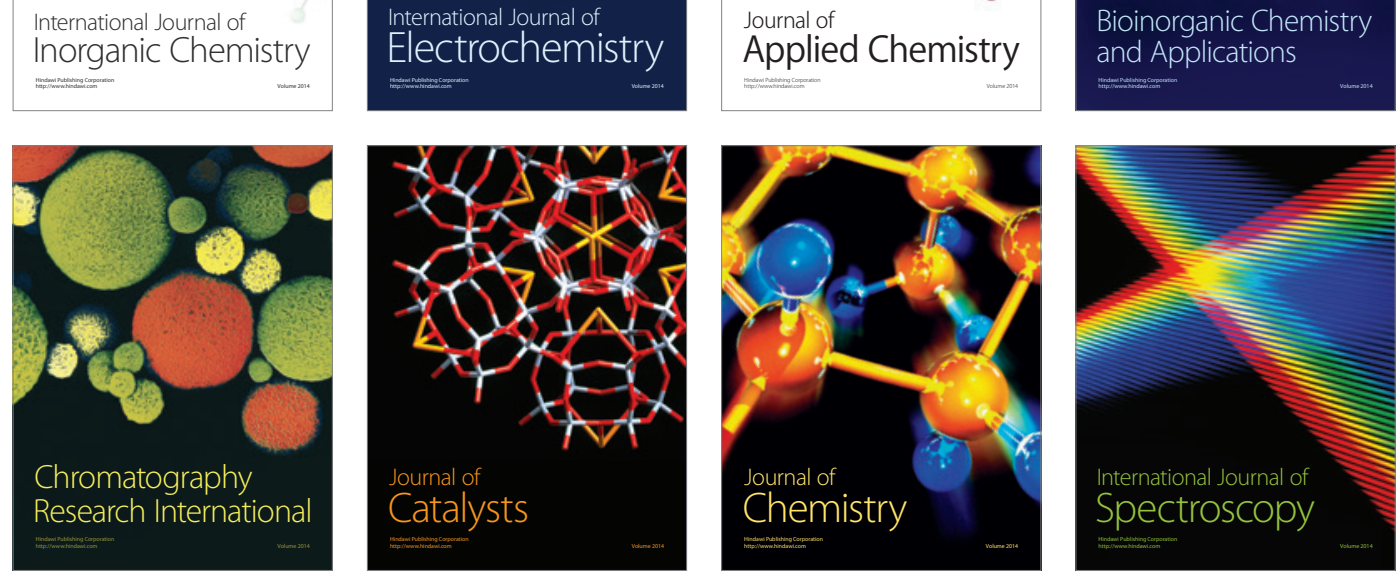